\title{
The role of purple pens in learning to prescribe
}

\begin{abstract}
Background

Medical doctors are required to prescribe drugs safely and effectively at qualification a skill that many feel poorly prepared to undertake. To better prepare doctors, a whole task approach that develops knowledge and skills, but also considers the effect of the complex clinical workplace on prescribing is optimal. We describe an evaluation of an experiential learning programme which allows senior medical students to gain experience with in-patient prescribing during their hospital assistantship.
\end{abstract}

Methods

A standard operating procedure (SOP) for medical student transcribing was implemented by the teaching hospitals associated with a single medical school. This included medical student prescriptions being written in purple ink. The evaluation consisted of an audit of transcribing activity and a student survey. We evaluated the usage of the initiative, adherence to the SOP and the propensity for error.

\section{Results}

The survey was completed by 38 out of a possible 108 fifth year students. All respondents agreed that the programme was helpful in aiding them learn about prescribing. Two hundred and forty seven prescriptions for 50 patients were audited. Twenty five percent of prescriptions written by students required some form of amendment by the supervising doctor or pharmacist. Three (1.2\%) prescription errors remained unidentified; none presented a patient safety risk.

\section{Conclusion}

The purple pen scheme affords medical students the opportunity to prescribe in the workplace where they face authentic challenges whilst safely contributing to patient care. Identification of prescribing errors, feedback and the learner's own reflection help learners to focus on areas for improvement in prescribing prior to qualification. 


\section{Introduction}

The General Medical Council (GMC) requires medical doctors to be able to prescribe drugs safely, effectively and economically at point of qualification (1). Newly qualified doctors perceive themselves poorly prepared for these tasks, a perception shared by educational supervisors (2). In the United Kingdom (UK), foundation doctors (those in their first two years of post graduate practice) write half of inpatient prescriptions (3), but make errors in $8.4-10.3 \%$ of those they write (4). Compelling arguments exist for better preparing graduates for the complexities of prescribing in the clinical workplace (5). However in the UK, medical students are legally prohibited from prescribing.

This paper describes the evaluation of an experiential learning programme, the 'purple pen'transcribing initiative, a whole school approach that allows senior medical students to gain experience with inpatient prescribing during their hospital assistantship with the aim of increasing both competency and preparedness.

\section{Methods}

\section{Context}

The context of this educational development was the final year assistantship at Keele University School of Medicine. This includes a 10-week acute hospital placement in which students take an apprenticeship role.

\section{The Programme}

The programme was developed by the principal author and the hospital's senior pharmacist. A standard operating procedure (SOP) for medical student transcribing (Figure 1) was developed and approved by the hospital's medicines safety committee. The aim was a concise but generalizable document that could be easily disseminated and read by all those involved in the process.

Crucial to patient safety was for all staff involved in the drug prescription and administration process to be cognizant of those prescription entries made by students. Therefore it was agreed that medical student entries exclusively would be in purple ink. 
of a whole task learning experience. Therefore transcribing was restricted to patients in whose care the student was actively involved and whose medication requirements they had verified. Each drug prescribed was only dispensed if countersigned by a doctor responsible for that patient. To enhance accountability and ensure feedback and learning, students were required to sign their entries and record their student number on the chart. Similarly, countersigning prescribers recorded their name and professional registration number on the chart. Any errors noted by the counter-signing doctor were amended and feedback given to the student. Errors missed by this process but detected subsequently (eg by the ward pharmacist) were recorded and fed back to all parties.

The transcribing process was introduced in 2015 by a multi-professional implementation team across Keele's four teaching hospital sites. The SOP alongside a verbal explanation about responsibilities within the programme were provided to each final year student and their supervising doctor(s). Senior pharmacists communicated the innovation to the ward teams to ensure understanding and local adherence. The process was subsequently refined: 1) Sourcing a darker shade of purple ink to be legible on scanned records. 2) Improving the uniformity of education sessions. 3) Introduction of a student assessment prior to issue of a 'purple pen'.

\section{Evaluation}

The evaluation consisted of an audit of transcribing activity as well as a student survey. The audit was undertaken over 2 consecutive weeks on 24 wards (12 medical, 12 surgical) at one hospital site in February 2018, midway through the final year. The aim was to evaluate the usage, adherence to the SOP and propensity for error. In order to evaluate the frequency of errors, every student prescription was checked against the British National Formulary (BNF). Any discrepancies were then discussed between NM and RK, who decided if they constituted an error. The online student survey was undertaken twice, in December 2017 and April 2018, at the end of the acute hospital placements.

\section{Results}

\section{Audit results}


During the audit period, 247 student prescriptions were written for 50 patients. Out of 24 students based on these wards, 17 students took part and identified themselves clearly in prescribing. Of 247 prescriptions written by students, 244 were written in purple ink. In $100 \%$ of prescriptions, drug allergies had been identified and documented prior to student prescribing. In 26 out of 247 (11\%), the student did not identify themselves (no student name or number documented on the chart). In 74 (30\%) the countersigning doctors failed to complete their name or GMC numbers on the chart. Corrections (defined as any amendment to a prescription which was then free of error) were made to 62 (25\%) prescriptions. Students corrected 9, the countersigning doctor corrected 27 and a pharmacist corrected 26 prescriptions. Amendments included correcting spelling, dose, route, legibility, drug diluent or adding additional information (e.g. "do not omit", changed dose etc). Three (1.2\%) prescription errors remained unidentified (spelling error, incorrect dose, specified more than one route) though none presented a patient safety risk.

\section{Student survey}

The survey was completed by $35 \%(38 / 108)$ of the students. The aim was to assess their frequency of transcribing and proportion of corrections, as well as the impact of transcribing on learning about error and perceived preparation for prescribing as a foundation doctor.

Engagement with the transcribing process on at least a daily basis was reported by $68 \%(26)$ of respondents (figure 2), with students writing up a broad range of drugs (figure 3). The majority (61\%) of students reported junior doctor most commonly countersigning their entries. Students were aware that transcribing was a formative process and expected to be informed if errors in their entries were identified. Respondents reported that up to $15 \%$ of their entries required correction by the countersigning doctor. Feedback on errors was usually received verbally whilst writing entries although onethird was given through correction of entries. Students reported a wide range of reasons for their errors (figure 4). All respondents agreed that the purple pen scheme was helpful in aiding their learning about prescribing and $97.2 \%$ of the respondents agreed that their confidence in prescribing had increased as a result. 


\section{Discussion}

Prescribing medicines is a core clinical skill in which newly qualified doctors are expected to be competent. Evidence globally suggests there are significant deficiencies in this area, something about which junior doctors are acutely aware (6). The aim of the final year student assistantship is to learn though immersed, supervised participation in clinical practice (7). Junior doctors and supervisors agree that prescription of drugs and fluids is one of the most important learning outcomes to achieve during an assistantship (8). To better prepare doctors a whole task approach that develops knowledge and skills, but also considers the effect the complex context of the workplace has on safe prescribing is optimal (9). Many medical schools in the UK lack a uniform approach in enabling medical students to transfer prescribing skills learnt in the classroom to the clinical workplace. It is therefore conceivable that some undergraduates may never actually practice prescribing in the clinical workplace until after qualification.

A pilot "pre-prescribing" innovation has been described elsewhere in which 12 volunteer medical students were allowed to transcribe on in-patient drug charts, with the condition of a doctor's counter signature before drugs were dispensed (10). The innovation was piloted on five medical wards in a single teaching hospital. No adverse events occurred throughout the study period although $2.5 \%$ of preprescriptions required amendment prior to countersignature.

This paper describes a whole school approach through which students gained supervised experience in prescribing for patients under their care. Our students' self-appraisal of their learning and the impact had on prescribing development was positive. No major adverse events to patient care were recorded, though minor errors were frequently identified and corrected prior to dispensing therapy. The results of the audit have been shared with the participating trusts to outline deficiencies in practice and reinforce adherence to the SOP through re-education

\section{Limitations and areas for future investigation}

Our audit of practice was conducted at a single hospital site over 2 consecutive weeks and therefore we may not have gained a fully representative sample of students' prescribing practice. Secondly, the 
student survey response rate was only $35 \%$. As such it is possible that some students had not had opportunity to fully engage with the intervention and those with a more positive attitude may be over represented in our sample. As reported previously (10), we found student uptake variable and therefore a qualitative study to understand the factors contributing to student engagement, their learning and professional development is warranted. Whilst electronic prescribing has been superseding paper prescriptions globally, our intervention was paper based. Whilst the authors suspect that the learning principles are similar, a study examining involving students in electronic prescribing would be interesting.

\section{Implications}

This transcribing programme afforded students the opportunity to prescribe in the workplace where they faced authentic challenges whilst contributing to patient care. Identification of, and feedback about, prescribing errors made within the authentic clinical workplace stimulated reflection within learners and identified areas of improvement before qualification. It is hoped that such a systematic approach to prescribing will facilitate medical student engagement and learning of the practicalities and perils of inpatient prescribing and thus ultimately enhance patient safety.

Word count 1499

\section{References}

1. General Medical Council. Outcomes for Graduates [online]. London: General Medical Council; 2015. Available at: https://www.gmc-uk.org/Outcomes_for_graduates_Jul_15_1216.pdf_61408029.pdf [Accessed 19 March 2018].

2. Tallentire VR, Smith SE, Skinner J, Cameron HS. The preparedness of UK graduates in acute care: a systematic literature review. Postgraduate Medical Journal. 2011;88(1041):365-371.

3. Ryan C, Ross S, Davey P, Duncan E, Francis J, Fielding S et al. Prevalence and Causes of Prescribing Errors: The PRescribing Outcomes for Trainee Doctors Engaged in Clinical Training (PROTECT) Study. PLOS ONE. 2014;9(1):e79802.

4. Illing J, Morrow G, Rothwell C, Burford B, Baldauf B, Davies C et al. Perceptions of UK medical graduates' preparedness for practice: A multi-centre qualitative study reflecting the importance of learning on the job. BMC Medical Education. 2013;13(1).

5. Dornan T, Ashcroft D, Heathfield H, Lewis $P$, Miles J, Taylor D et al. An in depth investigation into the causes of prescribing errors by foundation trainees in relation to their medical education EQUIP study. London: General Medical Council; 2009. Available online: www.gmc- 
uk.org/FINAL_Report_prevalence_and_causes_of_prescribing_errors.pdf_28935150.pdf [Accessed 19 Mar. 2018].

6. Hilmer SN, Seale JP, Le Couteur DG, Crampton R, Liddle C. Do medical course adequately prepare interns for safe effective prescribing in New South Wales public hospitals? Internal Medicine Journal. 2009; 39: 428-434 doi:10.1111/j.1445-5994.2009.01942.x

7. General Medical Council. Clinical Placements for Medical Students: Advice supplementary to Tomorrow's Doctors (2009). London: General Medical Council; 2011 p. 15-20. Available at: https://www.gmc-uk.org/-

/media/documents/Clinical_placements_for_medical_students guidance_0815.pdf_56437824.p df [Accessed 30th September 2018]

8. Tallentire VR, Smith SE, Cameron HS. Designing a purposeful assistantship. The Clinical Teacher. 2012; 9: 210 - 215. doi: 10.1111/j.1743-498X.2012.00553.x.

9. McLellan L, Tully MP, Dornan T. How could undergraduate education prepare new graduates to be safer prescribers? British Journal Clinical Pharmacology. 2012; 74:4 605 - 13. doi: 10.1111/j.13652125.2012.04271.x.

10. Smith SE, Tallentire VR, Cameron HS. Pre-Prescribing: a safe way to learn at work? The Clinical Teacher. 2012; 9: 45-49. doi: 10.1111/j.1743-498X.2011.00506.x. 
Figure 1

\section{Medicines transcription for undergraduate medical students standard operating procedure}

1. Undergraduate student must utilise indelible purple ink when writing on prescription charts.

2. Before making any entry on the prescription chart the undergraduate student must document their name and Keele University student number on the front of the chart.

3. Undergraduate students are only permitted to transcribe drugs for patients whose care they are actively involved with.

4. The student must enquire about and document drug allergy and sensitivity on the prescription chart prior to undertaking medicines transcription.

5. Medicines to be transcribed onto the chart should be verified against another source(s). These include the patient, the patient's reconciled medications list (in the medical record), their primary care record or if commencing a new drug, with the qualified prescriber responsible for the patient's care.

6. If a student is unfamiliar with the medication to be transcribed, the dosage, dosing interval and route of administration must all be checked against the BNF prior to transcription on the chart.

7. Once the undergraduate student has completed their transcription they must:

a. Sign for each drug transcribed in the additional information box next to the drug.

b. Present the chart to a nominated medical prescriber, who is directly involved with the patient's care [Foundation doctor (once Trust training completed), core trainee, middle grade or senior doctor]. Note: Locum doctors and nonmedical prescribers may not act in this role.

c. Ensure that all drugs transcribed are checked and signed by the nominated medical officer.

d. Ensure that any errors are corrected. The students must also reflect on the error and ensure necessary learning is completed and include as a written report in their learning portfolio.

e. If a nominated medical prescriber is unavailable the student must strike through the transcribed item or destroy the prescription chart.

8. Once the transcription has been checked the qualified prescriber must document their name, signature and GMC number on the front of the prescription chart. They must then sign each transcribed medication entry with black indelible ink.

9. If the qualified prescriber identifies any error in transcription they must amend the error and ensure the student receives feedback and understand the nature of the correction required.

10. The qualified prescriber retains responsibility for ensuring the correctness of all medication transcribed on the prescription chart.

Figure 2

\section{How often were you able to use your purple pen whilst on placement?} Not at all

Less than once a month

Once a month

2 to 3 times per month

Once a week

Multiple times a week

Once a day

Between 1 and 3 times per day

More than 4 times per day

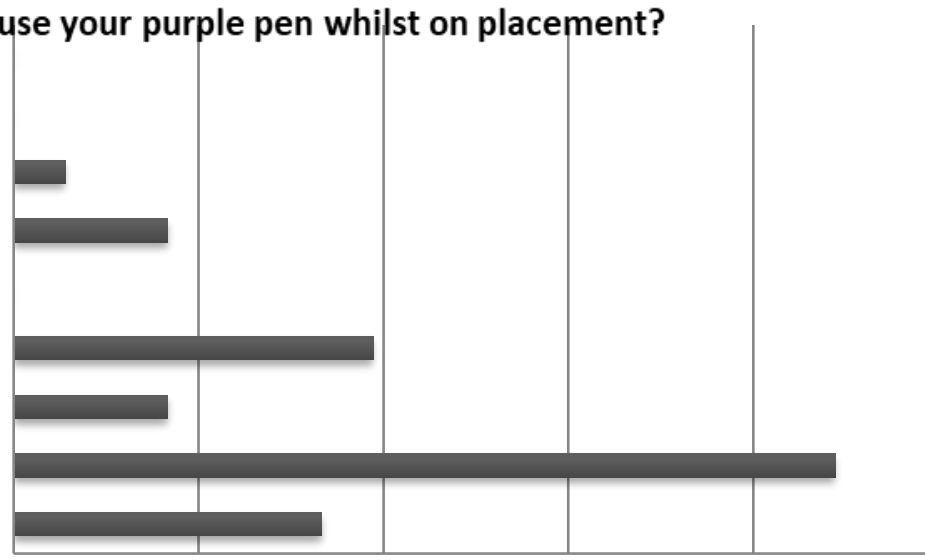


Figure 3

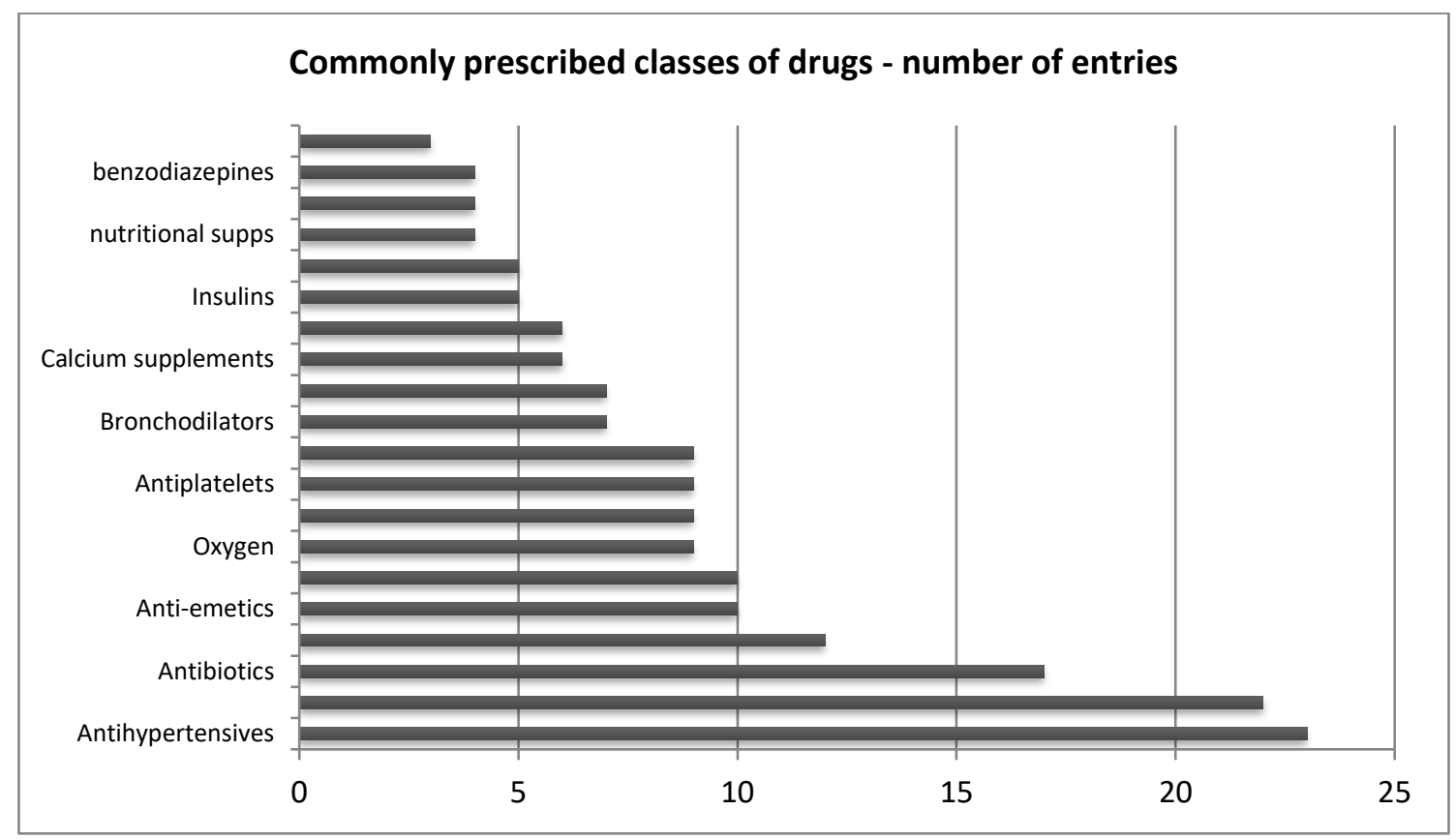




\title{
Chart Title \\ Why do you think your prescriptions needed correcting?
}

\author{
Other (please specify): \\ The handwriting was illegible
}

The supervising clinician failed to countersign the medication and the prescription was not struck out

The drug was unsuitable for the patient e.g. contraindication

The same drug was written up twice

Incorrect route was specified

Incorrect dosage of drug written

Incorrect frequency of drug specified

The incorrect subtype of drug was written up e.g. Atorvastatin/Simvastatin

The incorrect drug was written up

Failing to fill out all areas of the prescription chart (e.g. not specifying dose/frequency)

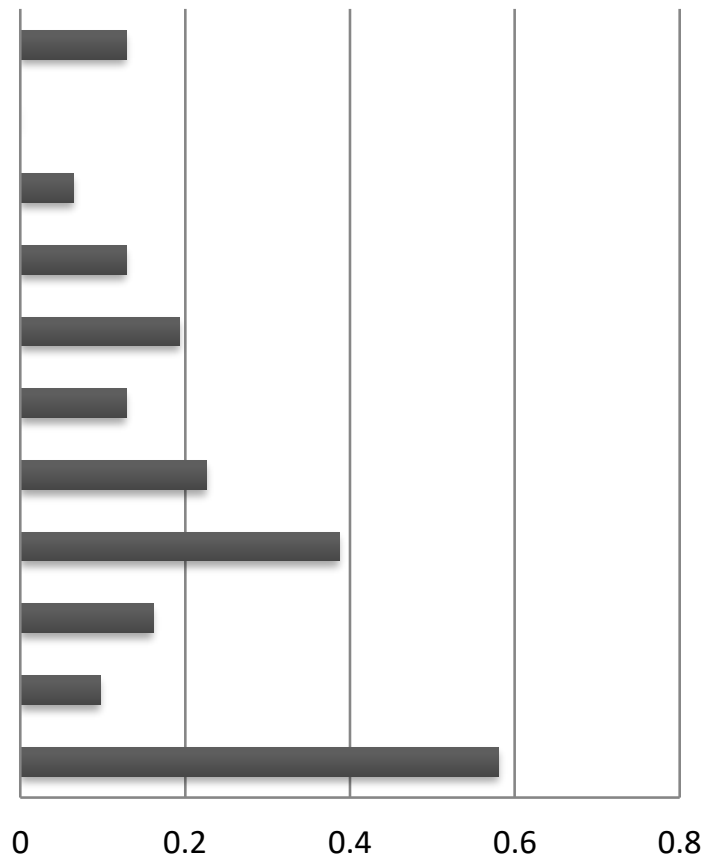

